\title{
Using Technology to Enhance a Project Management Course in the United Arab Emirates
}

\author{
Tony Jewels \\ Al Ghurair University, Dubai, \\ United Arab Emirates
}

tonyjewels@agu.ac.ae

\author{
Rozz Albon \\ Sharjah Womans College, HCT, \\ Sharjah, United Arab Emirates
}

r.albon@hct.ac.ae

\author{
Carmen de Pablos \\ Rey Juan Carlos Universidad, Madrid, Spain
}

carmen.depablos@urjc.es

\begin{abstract}
There is little doubt that advances in technology have provided unprecedented opportunities to develop more effective learning platforms, with the aim of ultimately providing better student learning outcomes. However, technological innovations on their own may provide little more than improvements in quality and productivity over previously used methods. Technology, regardless of how advanced the technology is, should never be used as a substitute for good teaching practice, but as a means of enhancing existing good teaching practices. This paper discusses how, over a period of 4 years, technology has been embedded into a project management course within the United Arab Emirates in order to provide students with a more effective learning experience.

The various technologies used in this example include videos of a case study project used in the course, a working example of the application software that was developed for the case study, audio recording of lectures and the construction of videos containing power point slides overlaid with previously recorded audio files.
\end{abstract}

Keywords: project management course, case studies, United Arab Emirates

\section{Introduction}

There's an old story about a drunk losing his house keys late one night. A by-passer sees the drunk searching for his lost keys beneath a street lamp and offers to help look for this fellow's keys. Eventually the passer-by gives up and asks the drunk whether he is sure that he lost his keys

Material published as part of this publication, either on-line or in print, is copyrighted by the Informing Science Institute. Permission to make digital or paper copy of part or all of these works for personal or classroom use is granted without fee provided that the copies are not made or distributed for profit or commercial advantage AND that copies 1) bear this notice in full and 2) give the full citation on the first page. It is permissible to abstract these works so long as credit is given. To copy in all other cases or to republish or to post on a server or to redistribute to lists requires specific permission and payment of a fee. Contact Publisher@InformingScience.org to request redistribution permission. under the streetlamp. The drunk replies that he knows that he lost them somewhere else but adds that under the streetlamp was the only place that he could actually see.

While the technology of the streetlamp certainly had the potential to assist the drunk to complete his task, i.e. finding his lost keys, this silly story shows how the application of technology can sometimes be used inappropriately without 
regard to its effectiveness. Norman, (1999) adapted the acronym I.T. from its usual meaning to that of "intrusive technology", when technology is used in such a way that it actually gets in the way of what you are trying to do.

In his book "The Invisible Computer", Norman poignantly related the story of how visitors to a sacred Chinese mountain routinely used their digital cameras to simply record the spectacular views, yet still preferred to sketch or paint in order to fully appreciate the beauty that they were witnessing. One of this paper's authors even sadly recalls how, as an amateur video maker, he had once been asked how he had enjoyed his recent trip to Rome, to which he replied he didn't know yet as he had not seen the video that he had made.

The introduction of technology is often initiated by bureaucrats implementing set procedures for teachers to follow. Such views disregard teachers capacities, "to make complex judgments based on deep understandings of students and subjects", (Darling-Hammond, 1994, p5). These topdown models of school reform view teachers merely as technicians "who narrowly construe the nature of the problems confronting them and merely carry out what others, removed from the classroom, want them to do", (Zeichner \& Liston, 1996, p4).

Reflective teachers think both about how they frame and then how to solve problems at hand, (Zeichner \& Liston, 1996, p5). The appropriate application of technology to teaching should, we believe, generally rest at the teacher level rather than be imposed by external sources. As Scheffler, (1968) pointed out, "Teachers cannot restrict their attention to the classroom alone, leaving the larger setting and purposes of schooling to be determined by others. They must take active responsibility for the goals to which they are committed, and for the social setting in which these goals may prosper. If they are not to be mere agents of others .... they need to determine their own agency through a critical and continual evaluation of the purposes, the consequences, and the social context of their calling", (p11). This paper reports on teacher generated technology initiatives that were introduced specifically to assist students in achieving better learning outcomes.

\section{Pedagogical Development of a Project Management Course}

In 2001, recognising the IT industry's poor project delivery performance and acknowledging different requirements for IT project management from other forms of project management, the Faculty of Information Technology of a leading Australian university, appointed an academic with extensive industry experience in IT project management to develop a specialised IT Project Management (ITPM) course as part of its postgraduate and undergraduate degrees.

The development and subsequent delivery of this new course was to be based around an actual project that this academic had been involved in, using real-world examples to illustrate the application of the various project management principles being taught. The project involved a fully robotic automated stock retrieval system (ASRS) warehouse designed and installed for a Taiwanese beverage company referred to as Super Cola Taiwan (SCT) by an Australian electrical engineering company referred to as Dag-Brücken (DB). The case illustrates how project management incompetency contributed to the failure of the project and ultimately to the winding up of the project organisation only 2 years after they had been awarded a prestigious export award for their innovative product.

The approach to teaching and learning design was deliberately developed to encourage a deep approach to learning on the part of students, (Marton \& Saljö, 1976). In following a process that required students to not only fully understand but also to apply the principles behind the concepts being taught, a case study that had earlier been written by the academic was introduced as a type of 'virtual environment' in which students were able to ensconce themselves (Jewels \& Ford, 2004) . Although still not equivalent to physically being a member of a team in a real project, an 
expected 'deep immersion' into an actual case, attempted to provide students with experience of the frustrations and elations that are part of most project environments, an appreciation of the real difficulties faced by project team members, and an understanding of the real purposes for using the theoretical constructs covered in the unit.

There were fundamental reasons why a case study approach was selected. Case method teaching can, according to (Mostert \& Sudzina, 1996), describe real-world problems that are too complex to approach experimentally (Glaser \& Strauss, 1967; Lincoln \& Guba, 1985; Patton, 1980). Arguments for the use of cases include:

- Cases investigate phenomena in a real-life context.

- Cases are appropriate where the boundaries between the phenomenon and the setting, as in classroom instruction, are not clearly evident

- Cases use multiple sources of evidence to describe the phenomenon under investigation. (Mostert \& Sudzina, 1996)

"It is the record of complex situations that must be literally pulled apart and put together again before the situations can be understood .... A good case keeps the class discussion grounded upon some of the stubborn facts that must be faced in real life situations." (Lawrence cited in Erskine, Leenders, \& Mauffette-Leenders, 1981, p.11).

The potential benefits of writing your own case study and subsequently using it in case method instruction provides an increased sensitivity to all teaching documents, enhanced effectiveness in preparation skills and the production of materials that help blur the distinction between the seminar room and the world "out there", (Barnes, Christensen, \& Hansen, 1994,p285). "Effective cases portray real people in moments of decision, faced with a need to take action and accept its consequences", and suggest that as a "second-best" alternative to apprenticeship good cases permit a "long look over the shoulder of a practitioner at work" (Barnes, et al., 1994,p287).

The initial delivery of the new course occurred in the Australian university's second 13 weeks teaching semester of 2002, attracting a total of 90 undergraduate students. Initial evaluation of the desired learning outcomes (Jewels \& Bruce, 2003) had suggested that the approach did not sufficiently encourage a deep approach to learning. These results appeared to confirm Entwistle's, (1988) findings that few students were "able to carry through all the component processes demanded by a fully deep approach which would have resulted in a deep level of understanding", (p28). It was felt, though, that it was worthwhile persisting with the single case study approach to see whether changes could be made to the pedagogy that would encourage more students to take a deep approach.

Jewels, Jones, \& Ford, (2003) reviewed the literature and noted the qualities of cases used for teaching purposes that were likely to better contribute to desired student learning outcomes comparing these qualities with those of the case used in the first offering of the unit. An original hypothesis was developed to evaluate the suitability of any teaching case for a particular unit:

Case suitability $=\mathrm{fn}(($ generic qualities of the case), (applicability to individual subject matter to be covered), (applicability to the expected general learning outcome) )

The results indicated that the original case would need to be rewritten if it was to comply with the generic attributes of case studies identified as helping to 'embed' students within a case environment. The case itself was then totally rewritten, expanding it from its original 5000 words to 11000 words, (Jewels, 2003).

Subsequent offerings of the course attempted to measure levels of deep v surface learning exhibited by students while also investigating the issue of how "embedded" students were in the case 
study. The case study approach was in line with the enhanced equation for learning (L) provided by Hicks, (1996): L = P + Q + ER, where ER, "one's own experience reflected on and revised" is added as a component to the more traditional elements of $\mathrm{P}$ (traditional programmed learning) and Q (questioned learning). According to Hicks,( 1996, p28), "learning by experience and reflecting on that experience can be most effective in helping students and practitioners acquire professional knowledge and skills". Because of its real world nature this case study certainly had the potential to provide experiential learning thus facilitating the ER component, yet even in its now enhanced form the case still only provided a written version of the various topics covered in this project management course. A question was then asked, "How might students 'embeddedness' within the case study be enhanced?"

\section{Embedding Technology into the Course}

It was fortunate that one of the authors of the case study, as an amateur video maker, had continually documented with video, the various stages of the project. This raw video footage was to provide the foundation for the creation of a 20 minute DVD.

The original video footage was recorded between 1996 and 1998 with an analogue video camera with tape storage. This video footage was original edited into a VHS format which was shown in a VHS player. When the technology became available, using a firewire, the original analogue video footage was converted into digital format that could be used in a video editing software application called Video Studio 8 and it was re-recorded in VCD format. Subsequent to this, when more advanced technology became available, using the original footage in digital format it was re-recorded again in DVD format. At each stage of its development, the video shown to students was used to enhance understanding of the case study that was being used in the course.

Some debate occurred over whether the video should be shown prior to students being given this 11000 word case study or after they had had a chance to understand what the case was about. Over a period of 7 years both options have been experimented with but it is still unclear, from student results, which option provides better learning outcomes. It was however clear that because this case was being used as background for most of the project management principles and theories being discussed in the course, it was necessary for students to become intimately familiar with the case as early in the course as possible. Regardless of the order of presenting the case and video, it was obvious that both learning objects ${ }^{1}$ needed to be presented in the early stages of the course.

Additionally, as this was an IT/IS based project management course it was decided to introduce students to the completed application software as soon it was believed that they understood the case study well enough for the software to make sense to them. The original database/graphical user interface (GUI) application software was presented to students showing how product could be moved robotically from one warehouse location to another. The only difference between the actual application software and the one being demonstrated was that this version used a simulator for each robot to provide continuous robot status data for the GUI rather than the robots themselves.

\section{Course Content}

Even when confronted with what has become a severely declining global demand for IT degrees, there still remains in many cases a failure to identify the now obvious changing industry needs for IT graduates identified in research such as that conducted by Zweig et al., (2006) and even earlier by Lee, Trauth, \& Farwell, (1995). The implications stretch beyond that of individual courses and

\footnotetext{
${ }^{1}$ A learning object is defined as, "Any entity, digital or non-digital, which can be used, reused or referenced during technology supported learning" (Hodgins, 2005 \#167).
} 
may even extend into the future of IT degrees themselves. The changing nature of industry demands for IT graduates was exemplified by Zweig, et al., (2006) who suggested,

"Organizations seeking to hire programmers have [only] a slight preference for candidates with undergraduate computer science or electrical engineering degrees. Those seeking to fill entrylevel positions requiring systems analysis skills tended to look more frequently at candidates with undergraduate business, MS/IS, or MBA degrees",

As an example of the differences between industry demands and IT degree curriculum, many project management courses still consist of little more than either understanding project documentation processes or identifying the nine sections of the PMIBOK, (2000).

Though this paper is specifically addressing the issues of embedding technology into teaching practices, it remains an imperative for educators to first ensure that the content of any course reflects what students need to learn in order to contribute to future learning as well as understanding how to apply their new found knowledge in practice.

The course thus set out to provide students with real-world knowledge and skills that they might be able to apply in becoming a member of an IT/IS project team.

\section{Context and Background}

This course was delivered in one of the three national United Arab Emirates (UAE) universities, each of which one of the authors has taught in for at least 12 months. The most obvious contextual issue faced within these universities is that undergraduate students in all three universities are segregated by gender. Also, for the majority of courses, the language of instruction is English, yet the official (and default) language of the region remains Arabic. Whenever a course delivery takes place in a region where the principle language of the country is not the language of instruction, it may result in situations where contact with teaching faculty may be one of the few occasions where students communicate in the language of instruction. This situation presents different issues than TESOL (Teaching English as a Second or Other Language) or TEAL (Teaching English as an Additional Language), and has more similarities with TEFL (Teaching English as a Foreign Language), (Jewels \& Albon, 2012).

Although audio recording of lectures has become fairly commonplace throughout western universities, this technology is not widely used in the three national UAE universities. It was believed that audio recording of lectures would provide two main benefits; as for native English speaking students it provided an additional resource that could be used by students to better understand content matter, but in the case of non-native English speaking students it also provided additional exposure time to English language. In 2008, a digital voice recorder, costing only a few hundred dirhams, was personally purchased and subsequently used to record all lectures given in all courses. The .wma files recorded were uploaded to Blackboard (each 75 minute lecture was approximately $14 \mathrm{Mb}$ in size) which could then be easily downloaded by students who could replay the lecture in their own time. The response to the introduction of the audio recordings was very positive, and became for students an expected feature of particular courses. Statistics tracking available with Blackboard indicated $>80 \%$ access rate. No official information was attained as to how students used these audio files but anecdotal conversations indicated that they we being replayed on MP3's, iPods and laptops.

The topic of video recording lectures was also considered but abandoned as cultural issues relating to female students would not permit this type of activity. The use of video recordings in other environments might however be considered an extension to audio recording likely to provide an additional worthwhile learning resource for students. 


\section{History of the ITPM course}

The IT Project Management course, using the rewritten case study, was first delivered concurrently to Australian undergraduate and postgraduate (MBA, Master of IT and Master of Engineering) students in 2003. It was initially an elective course but its popularity and the realisation of its practical applications for students led it to becoming in 2007 a core course in all the undergraduate IT degree specialisations offered by the university. It was to become a multiple prize winner, first at the college level, then at the university level and ultimately at the national level, receiving the citation .... "For establishing real-world perspectives of knowledge intensive project environments, providing students with state-of-the-art skills which enable them to become valuable project team players" (Carrick Institute, 2007).

From 2008 -2011 the same course, which was renamed MIS Project Management, was delivered to undergraduate students at a national university in the United Arab Emirates. Based on student feedback together with increasing enrolments, the course remained a popular one with UAE students. In Fall semester 2011 however the same format was used in another national university in the United Arab Emirates where the course had reverted back to its original name of IT Project Management. The 13 female students enrolled in this delivery of what had become by that time a mature course were decidedly different in their expectations of what, for them, constituted a worthwhile course. In their end of course student evaluation of the learning experience (SELE) feedbacks some students gave it very low marks, which was ultimately to result in the discontinuation of this version of the course at this university.

The evaluation of student learning for this course had for the previous 10 years been that of formative rather than summative assessment, $\{\mathrm{Nicol}, 2006 \# 112\}$. Weekly tutorial questions covering practical issues associated with that week's theoretical content had always been used for faculty to better understand students understandings of the topics in order that emphasis could be better directed in subsequent teaching. This assessment method concomitantly provided students with the opportunity to better understand the standards required in the course.

The Estimation and Metrics tutorial question for example was of the type ...

Use the Dag-Brücken case study as background to this tutorial.

Q1. What sort of estimation techniques and metrics would you have employed in order to avoid the lack of progress clearly evident in this project?

Q2. Why do you believe that appropriate metrics and estimation techniques were not used in this project?

Q3. How might the use of appropriate metrics and estimation techniques have contributed to a greater chance of success in this project?

Thirteen of these types of group tutorials each contributing to up to $3 \%$ of the overall assessment mark (with a maximum of 30\%) had in past offerings resulted in most students achieving either the maximum $30 \%$ or close to it. In the Fall semester 2011 offering only one group of three achieved the maximum mark which when compared with previous experiences clearly indicated that students were not performing at an appropriate level. Seven of the thirteen students had ended with final grades of less than B-, with two students achieving failing grades of F.

In the following semester (Spring 2012) there was a student revolt with all but one enrolled ITPM students withdrawing en masse from the course following the introductory first week. There was however one student who persisted with wanting to continue the course, yet it was impractical to provide the traditional lecture format for a single student. The course coordinator was requested by his college to provide the ITPM course for a single student who was, because of timetable clashes, unable to attend classes in the traditional lecture/tutorial format. The university itself 
was, at that time, investigating and experimenting with alternative forms of on-line teaching delivery and the challenge of developing a course that eliminated the requirement for students to regularly attend traditional classes, without diminishing the learning outcomes was indeed a timely challenge. Thus, this was the motivation to design a different version of the course and ultimately the raison d'être of this paper.

\section{The New Version}

Over time there had been a library of learning objects collected which included:

- 10 semesters of PowerPoint lecture slides

- 4 semesters of audio recordings of interactive lectures

- Multiple versions of tutorial questions relating to individual topics

- A 20 minute video of the DB-ASRS project

- A working copy of the application software used in the project

- An extensive library of readings associated with the course

This version of the course was to be developed on behalf of one Emirati female undergraduate student and was to be a pilot for other courses to be delivered in non-traditional ways. Although this student was unable to attend scheduled university class times she was prepared and able to attend one-on-one instructional sessions with the faculty member running the course. Subsequently single 15-20 minute weekly sessions were arranged where the student would visit the faculty member's office.

The structure of the assessments throughout this course was to be the same format used for the more traditional lecture format in previous semesters and consisted of:

- Thirteen weekly tutorial questions ( $3 \%$ each) based on selected topics covered in that week (maximum 30\%).

- A mid semester report interpreting project management principles and how the project might have increased its chances of success (30\%)

- A final 2 hour exam consisting of short answer explanations and essay type responses requiring interpretations/applications of project management principles $(40 \%)$

An application software package distributed by Corel called Video Studio 12.0.98.0 Pro, which had been personally purchased by the faculty member, was used to create video files in FLV format that could be loaded onto the university's Blackboard learning management system for eventual downloading by the student. This application software did allow for the videos to be produced in MPEG-4 formats for use in iPads or other types of mobile devices but issues with the sizes of files that could be loaded on the university Blackboard system meant that the smaller .flv formats were deemed to be the most appropriate. No exceptions were permitted by the university to accommodate this pilot study and for reasons still unknown, even .flv files were unable to be loaded onto Blackboard part way through the course. The approximately $15 \mathrm{Mb}$ files were still too large to be sent as attachments with the university webmail systems and as a fall-back position DVD's were produced and physically handed to the student, when she came to the office for her instructional sessions.

The number of learning objects collected for this course meant that any of the audio files relating to a particular topic could be used as the foundation for the video file. Similarly, any of the PowerPoint slides relating to the topic could be embedded as images. PowerPoint has an option to save any existing file in a number of picture formats, eg .tiffs or jpegs. The saved sets of tiffs or jpegs could then be used as images which are added to the base line audio files. It is simply a matter of extending the duration of the image to correspond with the audio component to produce 
a set of PowerPoint slides that duplicates a previously presented traditional lecture. This technique includes student comments, questions and responses from the sourced traditionally presented lectures. It contrasts with what has been described as 'talking heads' where someone simply creates an on-line narrative lecture. This new approach better duplicates the dynamics of a traditional interactive lecture, providing a more realistic environment for student learning.

The original case study video was given to the student to watch in her own time in a DVD format. Ensuring that the student had read the case study first the video was given to the student in week 3 , after she had completed the week 2 tutorial question of:

\section{Summarise what happened in the Dag-Brücken ASRS project, explaining why you think the project failed.}

The same tutorial question was presented again to the student as tutorial 13 and was used by both the student and the faculty member to reflect on what the student had learnt throughout the course.

Within the ITPM course there are a series of project management principles and practices that need to be understood properly if appropriate project decisions are to be taken. As an example, the need to undertake a project risk management strategy can fundamentally be thought of as a guide to selecting other strategies, such as an appropriate development methodology and how to estimate project progress (metrics). This type of advanced student learning outcome in a traditional attendance course was normally discussed and 'teased out' in group tutorial sessions, where multiple students contributed to a group solution. Describing and using this brainstorming technique which can be summarised as 'Looking for a solution that no individual could identify, but which a group could' would always be challenging with only a single student attending the 15-20 minute weekly instructional sessions. This was indeed to prove the most difficult concept to duplicate from the group environment setting with the instructor needing to be cognisant of the need for a student to develop solutions on their own, but still providing enough of the type of support that would normally have come from other students. The student involved in this pilot study was however both hard working and highly intelligent and ultimately did not have too much difficulty grasping these concepts, although less capable students might not have been able to meet these objectives. On reflection however, not all students in the more traditional delivery mode were able to properly grasp these concepts.

\section{Outcomes}

This ITPM course had been delivered in a traditional lecture/tutorial format over a period of more than 8 years at two Australian universities and two United Arab Emirates universities. The assessment methods and standards had been consistent across the 4 universities and it was felt that to properly evaluate the learning outcomes from the new method the same methods and standards should be applied.

Comparing the learning outcomes from this pilot study only with the learning outcomes from the previous semester's traditional delivery at the same university would have been futile as there was a noticeable lowering in overall standard between that offering and each of the previous offerings at the other three universities. A comparison was therefore made between the outcomes of the single student with the standards of the other UAE university and the two Australian universities. However, if a comparison was made with the previous semester outcomes, the student would have been a clear 5\% higher mark than that earned by the previous semester's top student. The standard of the student compared favourably with each of the top students at the other three universities and she would have earned her A in any of the other institutions. 


\section{Summary}

This hybrid delivery method of an IT project management course was brought about by the need to create an alternative delivery method for a single student who was unable to attend a traditional lecture/tutorial format course. The learning outcomes achieved in this pilot study indicate that it is a valid alternative to the traditional delivery methods.

The particular course was however a mature one already possessing a large number of learning objects which could be embedded into any new delivery method. The course already contained clear learning outcomes and regardless of the delivery method, its assessment methods and standards were identical.

It was a pilot study with a single student, who happened to be a hardworking and highly intelligent individual who was motivated to achieve the course learning outcomes. Whether the excellent results achieved by this student could be duplicated with less committed students remains a matter of conjecture, but the results of this pilot study have indicated that it is still a viable alternative to the more traditional form of delivery.

One of the key reasons why this pilot study could be undertaken at such short notice was that it was organised entirely by the faculty members themselves rather than relying on input from university administrators. The technology and its components e.g. digital audio recorder, video editing application software, project videos, and the project software itself, were all acquired personally with only the PowerPoint software and the Blackboard learning management system being supplied by the university. It is not clear whether such an elaborate course could indeed ever be developed by administrators who might be unfamiliar with the course content. It is also not clear whether administrators would be willing to provide encouragement to any faculty willing and able to create such courses on their own. In this particular example, after the original request to deliver this course to a single student was made by administrators, no further assistance was ever forthcoming or acknowledgement of the success of the pilot study ever made.

In this pilot study, technology has been applied to enhance the delivery of an existing course resulting in a single student achieving comparable learning outcomes with that of top students in previously delivered traditional courses. The question remains therefore of who should be primarily responsible for the application of technology in teaching ... administrators or the teachers themselves?

\section{References}

Barnes, L. B., Christensen, C. R., \& Hansen, A. J. (1994). Teaching and the case method: Text cases and readings, 3rd edition. USA: Harvard Business School Press.

Carrick Institute. (2007). 2007 Carrick citations for outstanding contributions to student learning. Retrieved May 5th, 2008, from http://www.carrickinstitute.edu.au/carrick/webdav/users/siteadmin/public/awards_citations_recipientsb yuni_aug07.pdf

Darling-Hammond, L. (Ed.). (1994). Professional development schools: Schools for developing a profession. New York, NY: Teacher's College Press.

Entwistle, N. (1988). Motivational factors in students' approaches to learning. In R. R. Schmeck (Ed.), Learning strategies and learning styles. USA: Plenum Press.

Erskine, J. A., Leenders, M. R., \& Mauffette-Leenders, L. A. (1981). Teaching with cases. London, Ontario: University of Western Ontario.

Glaser, B. G., \& Strauss, A. L. (1967). Teaching and the case method. Boston MA: Harvard Business School. 
Hicks, R. E. (1996). Experiential learning in a postgraduate project management programme. Education + Training, 38(3), 28-38.

Jewels, T. (2003). The Dag-Brücken ASRS case study. Journal of Information Systems Education: Special Issue on IS Teaching Cases, 14(3), 247-257.

Jewels, T., \& Albon, R. (2012). "We don't teach English, we teach in English": Teaching non-native English speaking university students. Learning and Teaching in Higher Education: Gulf Perspectives, 9(1).

Jewels, T., \& Bruce, C. (2003, June 24-27). Using a case method approach in an IT project management curriculum: A long look over the shoulder of a practitioner at work. Paper presented at the Informing Science + IT Education Conference, Pori, Finland.

Jewels, T., \& Ford, M. (2004). A single case study approach to teaching: Effects on learning \& understanding. Journal of Issues in Informing Science and Information Technology, 1(1), 359-372.

Jewels, T., Jones, W., \& Ford, M. (2003, 26-28th November). A study of cases: Evaluating requirements. Paper presented at the 14th Australasian Conference on Information Systems, Perth, Western Australia.

Lee, D. M. S., Trauth, E. M., \& Farwell, D. (1995). Critical skills and knowledge requirements of IS professionals: A Joint Academic/Industry Investigation. MIS Quarterly(September), 313-340.

Lincoln, Y. L., \& Guba, E. G. (1985). Naturalistic inquiry. Beverly Hill CA: Sage.

Marton, F., \& Saljö, R. (1976). On qualititative differences in learning: 1.Outcome and process. British Journal of Educational Psychology, 46, 4-11.

Mostert, M. P., \& Sudzina, M. R. (1996, February). Undergraduate case method teaching: Pedagogical assumptions vs the real world. Paper presented at the Annual Meeting of the Association of Teacher Educators, St Louis MO.

Norman, D. A. (1999). The invisible computer. Cambridge MA: MIT Press.

Patton, M. Q. (1980). Qualitative evaluation methods. Newbury Park: Sage Publications.

PMI. (2000). A guide to the project management body of knowledge. White Plains: Project Management Institute Inc.

Scheffler, I. (1968). University scholarship and the education of teachers. Teachers College Record, 70(1), $1-12$.

Zeichner, K. M., \& Liston, D. P. (1996). Reflective teaching: An introduction. Mahwah, NJ: Lawrence Erlbaum Associates Inc.

Zweig, P., Kaiser, K. M., Beath, C. M., Bullen, C., Gallagher, K. P., Goles, T., et al. (2006). The information technology workforce: Trends and implications 2005-2008. MIS Quarterly Executive, 5(2), 101-108. 


\section{Biographies}

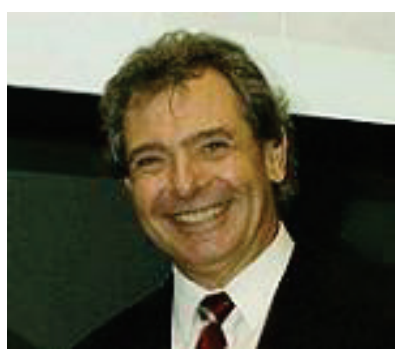

Tony Jewels, PhD, is an Associate Professor in the College of Business Studies of Al Ghurair University in Dubai, United Arab Emirates. He teaches MBA courses within that university's Project Management specialisation as well as Operations Management and MIS with an emphasis on Enterprise Resource Planning. His latest research focuses on cultural issues associated with business and information systems in the Middle East. A founding member of the Informing Science Institute he has attended InSite conferences in Pori, Rockhampton, Flagstaff, Manchester, Ljubljana and Varna while based in his native Australia and is now returning after a four year absence.

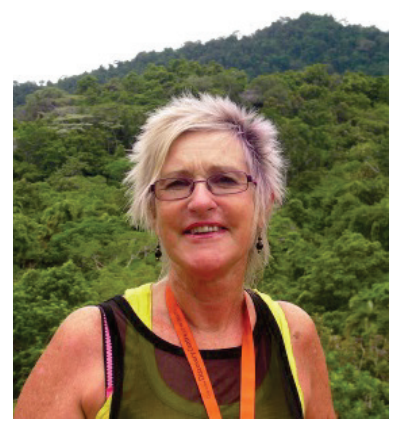

Rozz Albon, $\mathrm{PhD}$, is the academic coordinator of the education department of Sharjah Woman's College, HCT, in Sharjah, United Arab Emirates. An educational psychologist her $\mathrm{PhD}$ thesis related to gifted students and she is currently researching the application of comic books to teaching. Her research has included research on team work within higher education, the teaching of subject matter to non-native English speakers and recognizing and responding to the group of students in higher education that she refers to as "brilliant minds".

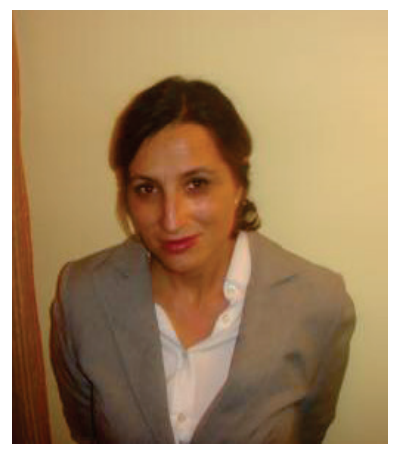

Carmen de Pablos, $\mathrm{PhD}$, is a Professor in the Business Administration Area at the Rey Juan Carlos University in Madrid, Spain from 1994. She is responsible for the $\mathrm{PhD}$ in Business Administration. She has chaired Doctoral Dissertations and Projects on the impact of information and communication technologies in organizational performance. She has presented communications in different international venues and has published 78 articles in specialized journals and 8 books. She is the Academic Director for the Master's Degree and Doctoral program in Business Administration and Entrepreneurship at the Rey Juan Carlos University and the co-director of the Master's Degree in Project Management, SAP-ERP Systems. 